\title{
Current perspective of the renewable energy development in Malaysia
}

\begin{abstract}
It is estimated that oil reserves will not last very much longer; thus, a switch to alternative energy solutions is crucial. The Malaysian government has already prepared to face the situation decades before. Many policies have been implemented, as well as programmes and initiative. Now, Malaysia is waiting for the ultimate solutions, the Malaysian Fit-in Tariff (FiT), which is scheduled to be implemented second quarter of 2011. This paper presents the main sources of alternative renewable energy in Malaysia and its potential as well as the main reasons Malaysia is turning to alternative energy solutions; to fully utilize its renewable energy (RE) resources, fulfill the energy demand in the future and to reduce carbon emissions. This paper also discusses the steps taken by the government in preparation for FiT and overcoming the barriers in RE development.
\end{abstract}

Keyword: Renewable energy; Energy demand; Energy policy; Fit-in Tariff 